\title{
Naget Khadda, Mohammed DIB, cette intempestive voix recluse
}

\section{Giuliva Milò}

\section{Q OpenEdition}

10 Journals

\section{Édition électronique}

URL : https://journals.openedition.org/studifrancesi/41365

DOI : 10.4000/studifrancesi.41365

ISSN : 2421-5856

\section{Éditeur}

Rosenberg \& Sellier

\section{Édition imprimée}

Date de publication : 1 juillet 2004

Pagination : 229-231

ISSN : 0039-2944

\section{Référence électronique}

Giuliva Milò, " Naget Khadda, Mohammed DIB, cette intempestive voix recluse », Studi Francesi [En ligne] 142 (XLVIII | I) | 2004, mis en ligne le 30 novembre 2015, consulté le 09 septembre 2021. URL : http:// journals.openedition.org/studifrancesi/41365; DOI : https://doi.org/10.4000/studifrancesi.41365

Ce document a été généré automatiquement le 9 septembre 2021.

\section{(c) (i) (9)}

Studi Francesi è distribuita con Licenza Creative Commons Attribuzione - Non commerciale - Non opere derivate 4.0 Internazionale. 


\title{
Naget Khadda, Mohammed DIB, cette intempestive voix recluse
}

\author{
Giuliva Milò
}

\section{RÉFÉRENCE}

NAGET KHADDA, Mohammed DIB, cette intempestive voix recluse, Aix-en Provence, Edisud, 2003, pp. 204

1 En cette année de l'Algérie, Naget Khadda, spécialiste consacrée de littérature maghrébine en langue française, s'empressait de faire publier, dès février, son étude sur Mohammed Dib, comme si elle eût voulu réparer au plus vite à un manque et rendre, à sa façon, l'hommage qui revenait de droit au plus grand écrivain, du moins encore en vie parmi ceux de sa génération, des lettres algériennes. Cette étude n'aurait pu venir plus à propos puisque, quelques mois après, le 2 mai, Mohammed Dib, à quatre-vingt-trois ans, allait disparaître de la scène du monde après avoir signé de son nom prestigieux un nombre incalculable de romans et avoir excellé dans tous les genres littéraires avant de voir son œuvre couronnée par le prix Mallarmé, décerné en 1998 pour son recueil poétique, L'enfant jazz.

2 Ouvrage de référence, le livre de Khadda veut s'adresser aussi bien aux lecteurs chevronnés de Dib qu'aux néophytes désireux de se familiariser avec l'imaginaire de l'auteur car il a le grand mérite de rendre accessible une œuvre difficile sans rien enlever à sa complexité et à sa richesse. Loin de la froideur critique, l'analyse du discours, tout en restant très rigoureuse, communique au lecteur l'estime et l'amour de Khadda pour l'écrivain.

3 L'étude appréhende la production complète de l'auteur à travers une analyse à la fois chronologique, thématique et esthétique. Se dessine peu à peu une personnalité qui, toujours fidèle à elle-même, n'a cependant jamais cessé d'évoluer depuis les premières compositions datées de la fin des années 40. Ainsi les écrits, tout en manifestant «un renouvellement constant des formes et des thèmes», n'en présentent pas moins une 
«grande continuité et une indéniable unité». Une unité donnée par ce long questionnement, entre émerveillement et désillusion, toujours inachevé sur l'opacité de l'existence et les contradictions de l'humaine condition. Tout conflue à mettre en valeur l'aspect existentiel de l'œuvre et à nous présenter Mohammed Dib surtout dans sa vocation de poète, sans cesse tourmenté par la quête du sens, abolissant aussi bien les frontières entre les genres que les frontières géographiques et récusant toute position prise et toute identité close. Les six chapitres qui structurent le livre critique mettent en lumière comment la voix dibienne, en faisant de moins en moins appel au référent, métaphorise le mystère de la création à travers un hermétisme toujours plus accentué:

4 1. Réalisme et engagement politique - 2 L'explosion fantastique - 3. Néoréalisme de la désillusion 4 Le cycle de l'exil - 5. La femme, l'amour - Le ressourcement de l'écriture.

Dans l'analyse de la trilogie algérienne [La grande maison (1952), L'incendie (1954) et Le métier à tisser (1957)] qui consacre l'écrivain trentenaire, Naget Khadda veut surtout dégager l'originalité d'une œuvre qui souscrit certes au code réaliste mais porte déjà en germe tout l'univers fantastique de Dib. Car si la vision du monde dibienne est au début tributaire des conditions historiques, la réalité coloniale s'inscrit dans une visée idéologique portée par le travail métaphorique de l'écriture qui opère une transfiguration remarquable des données. À cela concourt aussi l'interaction de narratiques émanant des deux héritages culturels de l'auteur. Dans un conflit des codes, deux réseaux sont mis en place: l'un indexé sur le discours en langue arabe, l'autre indexé sur le discours en langue française qui s'entrecroisent et se télescopent. Ce jeu contradictoire de distance et d'adhésion à l'égard du français, comme langue de travail, signale au départ la posture particulière de Dib, à la fois au cœur et à la lisière de tout système. C'est à partir de ces éléments essentiels que Naget Khadda voit évoluer la poétique dibienne.

6 Elle considère Un été africain (1959) comme une œuvre marquante, puisqu'elle va assurer la transition. Elle signale l'influence des Américains Dos Passos, Faulkner, mais aussi de Virginia Woolf, sur la sensibilité littéraire de l'auteur et sur le renouvellement des formes. L'univers maintient encore un solide ancrage dans le référent mais se précise comme «laboratoire» d'investigation où prime l'indétermination du sens. L'écrivain, est prêt à questionner le monde et non pas à délivrer des leçons. Dib adopte la poétique de la suggestion, de l'ambiguïté, des demi-teintes. La multiplication des points de vue, la déconstruction de la linéarité se précisent. La fonction du héros se répartit entre plusieurs acteurs dont les itinéraires s'entrecroisent.

7 C'est avec Qui se souvient de la mer (1962) qu'explose le fantastique dibien. L'esthétique réaliste est définitivenment abandonnnée. La fonction de communication devient à dominante poétique, l'accent se déplace sur la fonction émotive. Dans un monde décidément hostile, sans repères spatio-temporels, le critique, sans laisser de côté la quête du sens, décrypte le travail de l'écriture. Dans un espace familier métamorphosé en lieu cauchemardesque, Naget Khadda suit les déambulations du narrateur à la recherche de la vérité qui s'offre à travers une écriture déroutante et néanmoins signifiante du caractère irrationnel et mystérieux de la vie même. Elle perçoit l'errance comme la figuration non seulement de la quête de soi mais aussi de l'itinéraire tortueux de la prise de conscience politique mais surtout du trajet d'initiation mystique vers la ville mythique. Elle insiste sur le thème de la quête mystique, et déjà préoccupation 
majeure de Dib, qui se met ici en place porté par la référence à l'islamisme chiite et à la Kabale mais aussi par la métaphore de l'amour-fou.

8 Le profond pessimisme qui parcourt La danse du roi (1968) puis le dyptique, Dieu en Barbarie (1970) et Le Maître de chasse (1973) illustrerait la désillusion de l'après indépendance. En face de l'Histoire, est esquissée une contre-Histoire, une Histoire en creux où sont mis à l'honneur les plus démunis. Le critique se met à l'écoute des multiples voix de ces existences frustrées et fait entrer le lecteur dans un univers singulier où le sens plein n'est jamais donné car l'obsession de la quête du sens est conditionnée par un manque irréfragable, le manque existentiel. La réflexion sur la religion investit de plus en plus le débat socio-politique et une narration fortement mystique différencie le dyptique des romans précédents. L'intérêt pour le sacré excède les limites de la tradition islamique qui se combine avec les références à la mythologie gréco-latine ou aux croyances judéo-chrétiennes pour signifier, en dernière analyse, la fascination pour le mystère, le secret, le sens abscons, la face ésotérique du monde. Le problème de l'identité est alors posé: l'identité devient une notion ouverte car elle n'est pas seulement à rechercher dans le passé et dans ses profondeurs culturelles, mais se conquiert plus sûrement dans une perspective d'avenir. Le critique prête surtout attention au travail de l'écriture qui, chez Dib, creuse le sillon de son inquiétude essentielle: produire du sens par-delà la multiplication des langages qui escamotent le réel, par delà la dispersion des langues qui encadrent différemment le même réel. Le roman prend alors sa juste place dans une orientation qui va se précisant et qui s'avère être «la quête de l'écriture».

9 Dans le cycle de l'exil, l'écriture, avec des procédures toujours renouvelées, devient le lieu d'élaboration d'une signifiance toujours plus riche dans des romans qui, dans l'ensemble, mettent en œuvre la métaphore mystique et le questionnement psychanalytique.

10 De Habel (1977) jusqu'aux Neiges de marbre (1990) en passant par Les terrasses d'Orsol (1985) et Le sommeil d'Eve (1989), l'exploration du drame de l'exil serre au plus près les tensions qui habitent les personnages. La quête de soi et de sa propre vérité prend chez ces héros errants la forme d'une ascèse qui se caractérise par la proximité des expériences d'Amour, de Mort et de Folie, toutes à l'origine du geste scriptural et inscrites dans l'empire de la théologie. Naget Khadda insiste sur la résonance sacrée de ce dernier cycle, point d'orgue d'une pensée qui jamais n'a cessé de s'interroger sur le mystère de la création. Cette résonance manifeste surtout un esprit et une manière de vivre qui ne sauraient aller sans une ascension de l'âme, sans une intuition de la splendeur à laquelle tout homme peut prétendre. Car c'est à l'avénement d'un «homme-roi» que les narrateurs exilés rêvent et toute leur quête est sous-tendue par un désir de plénitude, par une aspiration à la totalité de l'être.

Dans leur tension vers l'accomplissement de soi, la communion fusionnelle avec l'Autre, que métaphorise le thème de l'amour-fou, constitue un passage obligé. C'est pourquoi notre critique consacre un chapitre entier à ce thème et à la manière dont il évolue au fil des romans. Pour elle, l'amour apparait comme un sujet nodal dans toute l'œuvre dibienne car il véhicule de façon éminemment émotionnelle la quête du sens (sens de la vie, de l'univers, de l'écriture), quête impliquant nécessairement l'exploration du problème de la communication et de la compréhension qui en est un corollaire. 
En dernière analyse, l'amour pour la femme servirait de tremplin pour accéder à l'amour suprême non incarné et qui englobe toutes les autres passions. Naget Khadda voit cette conception mystique d'inspiration platonicienne, théorisée par les maitres du soufisme et par les poètes arabes du Xème et XIème siècles, concurrencée dans le texte par une vision profane et moderne de la passion amoureuse telle qu'elle est vécue par les surréalistes. Il en ressort une vision complexe du personnage féminin qui conquiert en tout cas chez Dib, non seulement une autonomie mais acquiert aussi une force de rayonnement qui l'associe au rang de héros.

13 Naget Khadda considère Dib avant tout comme un poète au sens premier de créateur. Elle nous convie à lire ses œuvres dans leur interaction, la production romanesque puisant le souffle de son écriture dans cette sorte de réservoir que sont les nouvelles, le théâtre et surtout la poésie. Dans le dernier chapitre nous devinons la prédilection accordée aux recueils poétiques qui nous livrent l'âme dibienne car «plus qu'un mode d'investigation, la poésie est un mode d'existence». D'Ombre gardienne (1961) à L'enfantjazz (1998), le dire poétique conduit à une confrontation du monde et du silence.. Le chant invite à ressentir, dans l'épaisseur du signifiant, les affres de l'expérience du monde. Le sens, chez Dib, est l'absence vertigineuse de sens qui n'exclut cependant pas la nécessité de la quête. La sensibilité critique sait cueillir pour nous la quintessence du dire quand l'indicible et l'innomable, à travers l'économie des moyens, surprend par sa clarté même. Cela parce que la poésie de l'Etre se tient au plus près de ce qui s'écrit, à savoir au plus près de soi-même, et l'écriture, en cherchant au plus profond de soi, s'universalise.

Le livre de Khadda une fois refermé, c'est avec modestie que nous aborderons ces florilèges, «joyaux dans leur écrin préservés». 